\section{REFIRENCES}

(ARDO, B. Rapports entre le niveau de vigilance et le cunditionnement chez l'animal. Journal de Physiologic, Paris, 1961, 53, 1-212.

BINDR A. D.. \& BI.OND, J. A time-sample method for measuring general ativity and its components. Canadian Journal of Psychology, 1958. 12, 74-76.

DLILACOUR, J., ALBE-IISSSARD, D., \& LIBOUBAN, S. Role chez le rat de deux noyaux thalamiques dans le conditionnement instrumental. Neuropsychology, 1966, 4. 101-112.

GROSS, C. G., CHOROVER, S. L., \& COHEN, S M. Caudate, cortical, hippocampal and dorsal thalamic lesions in rats: Alternation and Hcbb-Williams maze performance. Neuropsychology, 1965, 3, 53-68.

REPLOGLE, A. Motivational effects of lesions in the thalamus. Unpublished M.A. thesis, McGill University, 1960.

SIEGEL, S. Nonparametric statistics for the behavioral sciences. New York: McGraw-Hill, 1956.

THOMPSON, R. Thalamic structures critical for retention of an avoidance conditioned response in rats. Journal of Comparative \& Physiological Psychology, 1963, 56, 261-267.

VANDERWOLF, C. H. Medial thalamic functions in voluntary behaviour. Canadian Journal of Psychology, 1962, 16, 318-330.
VANDERWOLF, C. H. The effect of medial thatamic lesions on previously established fear-motivated behaviour. Canadian Journal of Psychology, 1963,17, 183-187.

VANDI:RWOLI, C. H. Effect of combined medial thalamic and septal lesions on active-avoidance behavior. Journal of Comparative \& Physiological Psychology, 1964, 58, 31-37.

VANDERWOLF, C. H. Warm-up effects in the avoidance performance of rats with medial thalamic lesions. Animal Behaviour, 1966, 14, 425-429.

VANDERWOLF, C. H. Effects of experimental diencephalic damage on food hoarding and shock avoidance behavior in the rat. Physiology \& Bchavior, 1967, 2, 399-402.

VANDERWOLF, C. H. Recovery from large medial thalamic lesions as a result of clectroconvulsive therapy. Journal of Neurology, Neurosurgery \& Psychiatry, 1968, $31,67.72$.

WAHLSTEN, D., COLE, M., \& SHARP, D. Facilitation of bar-press avoidance by handling during the intertrial interval. Joumal of Comparative \& Physiological Psychology, 1968, 65, 170-175.

WARREN, J. M., \& AKERT, K. Impaired problem solving by cats with thalamic lesions. Joumal of Comparative \& Physiological Psychology, 1960 57, 207-211.

\title{
A comparison of morphine and food deprivation on wheel activity
}

RONALD C. TROST $\dot{T}^{l}$ and PAUL D. KNOTT, University of Denver, Denver, Colo. 80210

Morphine-addicted rats, tested under four different abstinence periods on wheel activity, showed no changes as did a group undergoing analogous periods of food deprivation. Several hypotheses are discussed concerning why morphine withdrawal might be expected to differ from hunger in its effect on activity.

Numerous studies have suggested that certain analogies exist between a morphine need state and other more classically manipulated motives, such as hunger. When, for example, morphine is abruptly withdrawn from an addicted animal, $S$ will (a) learn a new response for morphine reward (e.g., Thompson \& Ostlund, 1965), (b) show classical conditioning to the environmental cues paired with this situation (e.g., Wikler \& Pescor, 1967), and (c) exhibit an increase in a variety of behaviors which are consistent with current notions of restless activity (e.g., Martin, Wikler, Eades, \& Pescor, 1963). The last analogy may be questioned, however, on the
In that food deprivation leads to a decrease in body temperature and typically produces an increase in whee] activity, it is surprising that no attempt has been made to establish the contingencies which may exist between morphine privation and wheel performance since hypothemia has repeatedly been observed as a symptom of narcotic withdrawal (e.g., Martin et al, 1963). Accordingly, this experiment was designed to assess the effects of both food and morphine abstinence on wheel activity as a function of four different deprivation periods in order to determine the nature of the similarities between the two "motive" states with respect to this measure.

\section{METHOD}

Subjects were 30 experimentally naive male hooded rats of the Long-Evans strain. At the beginning of the experiment, they ranged between $80-100 \mathrm{~g}$ in weight and were 35 days old.

Thirty activity wheels, $15 \times 41 / 2$ in., with floors of $1 / 2$-in. wire mesh, were mounted on a large rack, 10 wheels per axel. Each wheel was provided with a simple mechanical counter and a racheting device which allowed the wheels to rotate in one direction only.

The Ss were housed in a separate room in $7 \times 10 \times 16$ in. cages, three per cage. Extraneous noise and stimulation were kept minimal during the entire experiment in both the home and testing environments, and indirect illumination was provided at all times by two 100 -W flourescent fixtures.

Beginning at age 35 days, each $S$ was handled every day until docile. Fifteen Ss were then randomly assigned to the drug-deprived group (Dd) and the food-deprived group (Fd). Group Dd was injected with an initial dose of $5 \mathrm{mg} / \mathrm{kg}$ ip of morphine sulfate twice daily at $9 \mathrm{a} . \mathrm{m}$. and 9 p.m. and received ascending doses bi-weekly until stabilization at $200 \mathrm{mg} / \mathrm{kg} /$ day on the $35 \mathrm{th}$ day. The volume of solution for each animal was kept constant during this time on a weight basis and usually ranged between .2 to $.3 \mathrm{cc}$ for a given S. Dilution of morphine sulfate within this volume increased every $3 \frac{1}{2}$ days. A similar schedule and dosage rate has been shown elsewhere to addict rats to morphine (Martin et al, 1963), and was maintained until the testing phase 32 days later. Group Fd was treated in a similar manner except for injections of $0.9 \%$ aqueous solution of sodium chloride in place of morphine sulfate at the same time and at volumetrically equivalent amounts. During this time, food and water were ad lib.

Immediately following a week of dosage stabilization, an adaptation phase was begun whereby each $\mathrm{S}$ was assigned to any one of 30 available activity wheels for $12 \mathrm{~h}$ per day. At the end of this period, $\overline{\mathrm{X}}$ revolutions/h 


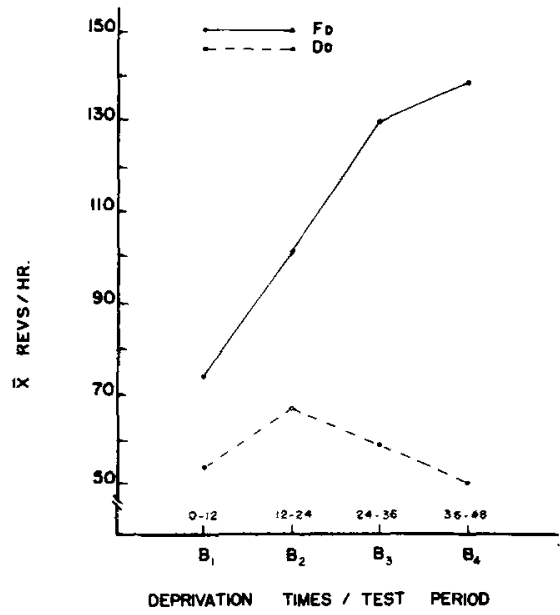

Fig. 1. Wheel activity for both groups as a function of hours of deprivation.

were scored for each $S$ until it became evident, between the 20 th and 25 th days, that all Ss had adapted to the activity wheels. To equate for frictional torque, random assignment to activity wheels was carried out during the entire experiment.

The test situation for an $S$ in either group consisted of four deprivation conditions: 0-12 h (B1), 12-24 h (B2), 24-36 h (B3), and $36-48 \mathrm{~h}(\mathrm{~B} 4)$. Both groups were tested under all four conditions, the order of B1,B2,B3, and B4, randomly assigned for each S. In order to (a) control for time of testing within a day and (b) insure that all Ss could be returned to a minimum of $48 \mathrm{~h}$ food or drug stabilization after $12 \mathrm{~h}$ in the wheels, a total of $96 \mathrm{~h}$ elapsed between any two test periods. That is, if on a given day an $S$ had been assigned to Condition $\mathrm{B} 4$, he was thereafter deprived for $36 \mathrm{~h}$, tested between $36-48 \mathrm{~h}$ in the wheel, and received a recovery period $48-96 \mathrm{~h}$ before beginning another "trial." In this way, all Ss received all four possible deprivation and recovery conditions in a random manner, thus making differences between Ss a function solely of food or drug deprivation.

\section{RESULTS}

The between-groups main effect, Fd vs $D d$, and the within-groups main effect, times of deprivation, were both significant beyond the .01 level of confidence $(F=14.04$, $\mathrm{df}=1$, and $\mathrm{F}=7.30, \mathrm{df}=3$, respectively), using a mixed design ANOVA. The interaction of groups and treatments was also significant $(F=13.89, \mathrm{df}=3, \mathrm{p}<.01)$, indicating that the $\bar{X}$ revolutions/hours for both groups varied depending on denrivation condition.

Figure 1 depicts the $\bar{X}$ revolutions $/ h$ as a function of the four deprivation treatments, BI , B2, B3, and B4. Whereas it appears that Group Fd was superior to Group Dd over all test periods, a $t$ test for Treatment $B 1$ between groups was not significant. In addition, the largest mean difference within Group Dd failed to meet the critical value needed for significance at the .05 level, using the Dunnett multiple comparison test. DISCUSSION

The results of this study do not support the notion that morphine need will lead to an increase in wheel activity in a manner similar to that of food deprivation. If it can be assumed that a deprivation-activity correlation infers a motive state, then the present investigation is in agreement with Khazan et al (1967) that (a) the restless activity due to acute withdrawal distress is probably unrelated to a motive for morphine and (b) the fundamental nature of a motive for morphine has yet to be demonstrated. Further, in that morphine privation in rats is typically characterized by a decrease in body temperature, a finding of no increase in wheel activity is not in accord with the hypothesis of Hall (1966) that decreases in body temperature as a function of some deprivation states lead to an increase in wheel performance. This point would be stronger if measures of body temperature had been obtained in the present study, but hypothermia associated with morphine withdrawal is well established(e.g., Martin et al, 1963).

Briefly turning to alternate interpretations of the data, there are several reasons why morphine withdrawal might be expected to differ from hunger in its effect on wheel behavior. Hall (1956) has suggested that food deprivation in rats increases wheel activity and the addition of extraneous noise or stimulation acts to further increase it. If withdrawal is a more stressful condition than hunger, thereby enhancing an organisms's sensitivity to incoming stimuli, the noise present during testing might have functioned to disrupt running-wheel behavior for drug-deprived animals even though it was kept minimal. Another issue, that of learning, may also be worth considering before an activity-wheel/morphine-deprivation analogy can be shown. In the present study, morphine-deprived $S s$ never engaged in behavior which could be associated with the reduction of acute withdrawal distress. Presumably, however, in Group Fd hunger cues had been paired with behaviors that successfully reduced such stimuli since birth. Under these circumstances, either the comparison between Groups Fd and Dd and/or the relationship between deprivation-activity could be inflated if hunger cues had come to direct as well as to energize the measured behavior.

\section{REFERENCES}

HALL, J, F. The relationship of external stimulation, food deprivation, and activity. Journal of Comparative \& Physiological Psychology, 1956, 49, 339-341.

HALL, J. F. The psychology of leaming. Philadelphia and New York: Lippincott, 1966. KHAZAN, N., WEEKS, J. R., \& SCHROEDER, L. A. Electroencephalographic, electromyographic, and behavioral correlates during a cycle of self maintained morphinc addiction in the rat. International Journal of Pharmacology \& Experimental Therapeutics, 1967, 155, 521-531.

MARTIN, W. R., WIKLER, A., EADES, C. G., \& PESCOR, F. T. Tolerance to and physical dependence on morphine in rats. Psychopharmacologia, 1963,4, 247-260.

THOMPSON, T., \& OSTLUND, W., JR. Susceptability to readdiction as a function of the addiction and withdrawal environments. Journal of Comparative \& Physiological Psychology, 1965, 60, 388-392.

WEASNER, M. H., FINGER, F. W., \& REID, L.S. Activity changes under food deprivation as a function of recording device. Journal of Comparative \& Physiological Psychology, 1960, $53,470-474$.

WIKLER, A., \& PESCOR, F. T. Classical conditioning of a morphine abstinence phenomena, reinforcement of opioid-drinking behavior, and "relapse" in morphine-addicted rats. Psychopharmacologia, 1967, 10, 255-284. NOTE

1. Reprint requests should be sent to $R$. C. Trost at the University of the South, Sewance, Tenn. 37375 . 